\title{
A organização do ensino de Matemática na primeira Escola Normal Secundária pública de Foz do Iguaçu (1958-1960)
}

\author{
Susimeire Vivien Rosotti de Andrade \\ Patrícia Sandalo Pereira
}

\section{Resumo}

Este artigo apresenta uma investigação acerca da organização do ensino da matemática na primeira turma da Escola Normal Secundária pública do município de Foz do Iguaçu. Buscar-se-á resposta para a seguinte questão: Como o contexto histórico influenciou na organização do ensino da matemática na primeira Escola Normal Secundária pública do município de Foz do Iguaçu? Realizou-se uma pesquisa de caráter bibliográfico e documental constatando que, na época da implementação da referida escola, o ensino normal seguia as determinações de Brasil (1946) e do estado do Paraná (1955-1958), evidenciando um alinhamento com a organização do ensino de matemática implementado no estado de São Paulo idealizado por Osvaldo Sangiorgi (1924-2017) que concebia a formação matemática dos futuros professores primários primordial para possibilitar mudanças no processo de ensino-aprendizagem. No entanto, a pesquisa documental nos arquivos inativos da escola indica ausência de registros destas inovações na organização do ensino da matemática e, somente, aparecem indícios de implementação no ano de 1960. Consideram-se que as dificuldades no período de criação da referida escola, entre elas: professores com a formação mínima exigida pela legislação, estrutura da instituição de ensino, bem como a dificuldade de deslocamento fora decisiva para a não efetivação da mudança na organização do ensino da matemática.

Palavras-chave: Organização do ensino da Matemática. Escola Normal Secundária. Contexto Histórico. 


\title{
The organization of Mathematics teaching in the first Normal Secondary Public School of Foz do Iguaçu (1958-196o)
}

\author{
Susimeire Vivien Rosotti de Andrade \\ Patrícia Sandalo Pereira
}

\section{Abstract}

This article presents an investigation about the organization of mathematics teaching in the first class of the Public Secondary School of the municipality of Foz do Iguaçu. The following question will be answered: How did the historical context influence the organization of mathematics teaching in the first Normal Public Secondary School in the municipality of Foz do Iguaçu? A bibliographic and documentary research was carried out to verify that, at the time of the implementation of this school, normal education followed the determinations of Brazil (1946) and the state of Paraná (1955-1958), showing an alignment with the organization of the mathematics education implemented in the state of São Paulo conceived by Osvaldo Sangiorgi (19242017) that conceived the mathematical formation of the prime primary teachers to enable changes in the teaching-learning process. However, documentary research in the inactive archives of the school indicates absence of records of these innovations in the organization of mathematics teaching, and only indications of implementation appear in the year of 1960. It is considered that the difficulties in the period of creation of said school, among them: teachers with the minimum training required by the legislation, structure of the educational institution, as well as the difficulty of displacement was decisive for not effecting the change in the organization of mathematics teaching.

Keywords: Organization of Mathematics Teaching. Secondary Normal School. Historical context. 


\section{Introdução}

O Ensino Normal, no período da criação da primeira Escola Normal Secundária de Foz do Iguaçu, em 1957, organizava-se seguindo a reforma de Gustavo Capanema, desta forma, o ensino secundário tinha dois ciclos, o primeiro - ginásio, o segundo subdividido em - clássico e científico, em ambos, a disciplina de matemática aparecia em todas as séries. Porém, nos cursos técnicos visando à formação profissional, como no ensino normal, no segundo ciclo, a organização do ensino de matemática limitava-se, apenas, à $1^{\mathrm{a}}$ série.

Cumpre lembrar que, neste período, Osvaldo Sangiorgi propôs uma modificação relacionada ao ensino de matemática para o ensino normal no estado de São Paulo, e enfatizava que estas mudanças oportunizariam aos futuros professores uma formação inicial que lhes daria condições de contribuir no processo de ensino-aprendizagem de seus alunos e destacou que suas inovações foram, também, abarcadas em outros estados entre eles o do Paraná.

Partindo disso, em 2017 o grupo de pesquisa Formação e Educação Matemática Formem que tem como objeto de estudo a formação de professores de matemática, corrobora com Valente (2013, p. 940) quando afirma que abordagem da matemática da escola básica numa perspectiva histórica "poderá contribuir com a formação matemática do professor, na medida em que possibilita ao futuro mestre travar experiências com a construção dos conhecimentos elementares matemáticos, ferramentas de trabalho do profissional".

Assim, realizou-se uma pesquisa de caráter bibliográfico e documental visando compreender a organização do ensino da matemática na primeira turma da Escola Normal Secundária pública do município de Foz do Iguaçu, criada pelo Decreto no 10.336 de 28 de maio de 1957. Buscar-se-á resposta para a seguinte questão: Como o contexto histórico influenciou na organização do ensino da matemática na primeira Escola Normal Secundária pública do município de Foz do Iguaçu?

Para apresentar a pesquisa o artigo foi organizado mediante três momentos: a trajetória que possibilitou a criação da Escola Normal Secundária pública em Foz do Iguaçu; como era vislumbrada a organização do ensino da matemática para o ensino normal e como foi implementada na Escola investigada.

\section{Breve trajetória da criação da primeira escola normal secundária pública em Foz do Iguaçu}

De acordo com Saviani (2005), o primeiro país que instituiu uma Escola Normal, que objetivava a formação de professores que atuaria no início da escolarização, foi a França no ano de 1795. Com relação ao Brasil essa preocupação emergiu somente após a sua independência quando, em 1827, aprova-se a lei das escolas de primeiras letras, corroborando, 
como esta afirmação ao indicar que os professores precisavam de treinamento adequado para implementarem o ensino mútuo.

Segundo Souza (2006), o ensino mútuo foi criado por Andrew Bell (1753-1832) e Joseph Lancaster (1778-1838), na Inglaterra, no começo do século XIX, e suas características reduziram os gastos com os professores, pois estes atendiam um número maior de alunos, pois o método propunha: alunos monitores, ensino simultâneo da leitura e da escrita, agrupamento dos alunos por matérias, criação de materiais didáticos especializados.

Neste sentido, a Lei Provincial no ${ }^{0}$ 10, de 04 de abril de 1835, criou a Escola Normal brasileira sendo considerada a primeira de caráter público de todo o Continente Americano, ficando o ensino das primeiras letras sob a responsabilidade das províncias, inclusive, a formação destes professores. Porém, as escolas normais eram criadas e fechadas aleatoriamente e, somente no período republicano houve avanços no ensino normal, sendo um dos motivos para a formação de núcleos urbanos e a transformação das províncias em estados federados, fomentando iniciativas individuais como as ocorridas no estado de São Paulo, que propôs uma reforma no ensino primário concebendo a formação dos professores peça chave para sua implementação.

Conforme Saviani (2013), outro ponto importante foi o movimento da Escola Nova, que defendia a educação obrigatória, leiga e gratuita, portanto, o Estado deveria assumir este compromisso implementando no país. No ano de 1932, vinte e seis educadores assinaram um Manifesto dos Pioneiros da Educação Nova indicando seus ideais e, apesar dos renovadores serem derrotados pelos conservadores, especialmente, no decorrer do Estado Novo, esses não os impediram de influenciar as políticas educacionais do país, visto que, muitos deles acabaram sendo convidados para trabalhar com as políticas educacionais nos governos da época.

Vale dizer que, como destacado anteriormente, a urbanização foi fator importante para considerar a escolaridade mínima como ponto para o desenvolvimento do país e a população começou a verificar a escolaridade como necessária à sobrevivência. Diante disso, oportunizou-se um espaço para discussões com a necessidade de se organizar a educação em nível federal abarcando essas necessidades, o responsável em propor novas diretrizes para o ensino na época era o ministro Gustavo Capanema, que aprovou as Leis Orgânicas do Ensino - 42 a 46 -, que organizaram o ensino, inclusive, o profissionalizante.

O referido decreto estabelece a formação dos professores da primeira fase da escolarização, organizada em ciclos. O primeiro, de quatro anos, objetivava a formação de regentes do ensino primário e funcionaria em Escolas Normais Regionais, destinada a alunos que tivessem os certificados primários completos e idade mínima de treze anos; o segundo, de três anos, referia-se ao ciclo colegial do curso secundário, que formaria o professor primário e ISSN 2526-2882

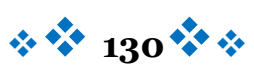


lhe possibilitaria o ingresso em alguns dos cursos superiores da faculdade de educação, seu funcionamento ocorreria em Escolas Normais Secundárias e nos Institutos de Educação. Este determinava, ainda, que para o ingresso no segundo ciclo os alunos deveriam ter concluído o primeiro ou tivessem certificado do curso ginasial, ter a idade mínima de quinze anos e, em ambos os ciclos, os alunos não poderiam ter mais de vinte e cinco anos.

Para Romanelli (1986), as expectativas com o Decreto-lei 8.530, de 02 de janeiro de 1946, equivocou-se em pontos fundamentais para a mudança no ensino primário da época, pois impôs uma idade para o ingresso. Dessa forma, negou a realidade existente, tendo em vista que o número de professores leigos que atuavam era alto e estes, também, necessitavam da formação inicial adequada para desenvolverem melhor sua atividade profissional. Outro ponto negativo era a limitação para a continuidade de estudos em nível superior dos alunos, que seria possível somente para alguns cursos da faculdade de filosofia. Cumpre lembrar que os outros cursos profissionalizantes também sofriam com esta imposição, na qual, o prosseguimento nos estudos em nível superior somente ocorreria se estes seguissem a área técnica, já determinada no momento da escolha do curso profissionalizante.

Saviani (2012) considera que, no primeiro ciclo do ensino normal, o currículo era centrado nas disciplinas de cultura geral e, somente, o segundo ciclo abarcava os fundamentos da educação e as alterações em sua organização ocorreram somente com a aprovação da Lei no 5692, de 11 de agosto de 1971.

No entanto, antes dessa nova organização ventos sopraram a favor dos cursos profissionalizantes, conforme salientou Almeida (2006), motivados pelas novas classes sociais, entre elas a burguesia industrial e financeira, o proletariado urbano e as camadas médias ligadas à burocracia do Estado, as empresas privadas e o setor de serviços, que começaram a reivindicar mudanças, uma delas relacionadas aos cursos profissionalizantes, pois consideravam inadequado os alunos terem seus direitos limitados na questão da continuidade dos estudos, em nível superior, pela escolha do curso profissionalizante e, também, o fato da não articulação da primeira etapa com os outros cursos secundários.

Nesse contexto, foram promulgadas algumas Leis de Equivalência na década de 1950 e uma delas assegurava aos alunos dos cursos profissionalizantes escolherem qualquer curso no ensino superior, desde que atendesse às seguintes exigências: complementação das matérias que não foram ofertadas no curso profissionalizante, exigida no curso superior escolhido e, também, a aprovação no vestibular. De acordo com Almeida (2006), o ensino normal acabava sendo influenciado pelas questões econômicas, sociais e políticas que ocorriam no país e sua organização relacionava-se diretamente às concepções de quem estava no poder.

No estado do Paraná, no período de criação da primeira Escola Norma Secundária pública de Foz do Iguaçu, as políticas educacionais sofriam, ainda, as influências das ISSN 2526-2882

$$
131 *
$$


concepções de Erasmo Pilotto (1910-1992), diretor da Escola de Professores de Curitiba e Secretário de Educação e Cultura do Paraná (1948-1950). Segundo Miguel e Alboni (2005), Erasmo Pilotto considerava que o ensino normal deveria corroborar para os futuros professores tornarem-se líderes das comunidades onde atuariam, consequentemente, deveriam conhecer as peculiaridades para, dessa forma, conseguirem intervir e motivar a todos acerca da educação como peça chave no desenvolvimento do estado.

Diante disso, os professores corroboraram para enfatizar que os hábitos, atitudes e valores urbanos eram superiores aos da zona rural e desprezavam, assim, a cultura da maioria dos alunos. Vale dizer que as políticas educacionais do estado do Paraná eram influenciadas pelo projeto maior vislumbrado pela Organização para a Educação, a Ciência e a Cultura das Nações Unidas - UNESCO que dialogavam com os pressupostos teóricos da Pedagogia da Escola Nova.

Inspirado nas ideias de Pestalozzi, Decroly e Montessori, ele colocou em prática os principais fundamentos da Pedagogia da Escola Nova, isto é, o aluno como centro do processo de ensino-aprendizagem, a metodologia ativa e a valorização da pesquisa para orientar a prática educacional. No Instituto Pestalozzi, instituição particular, com caráter experimental que funcionou como laboratório das ideias da Educação Nova, Pilotto articulou a vivência pedagógica considerando o desenvolvimento do educando. Tal desenvolvimento era estimulado por atividades que colocavam o aluno em contato com as melhores obras da cultura humana na música, nas artes plásticas e na literatura e desenvolvidas num ambiente acolhedor (MIGUEL, ALBONI, 2005, p. 6) [Grifo nosso].

Conforme as autoras, Erasmo Pilotto corroborava com o referido projeto, assim, na década de 1940, implementou-se no estado do Paraná a política de expansão das escolas de formação de professores, primeiramente, com os cursos normais regionais, levando em consideração que os professores formados nos centros urbanos não demonstravam interesse em desenvolver suas atividades profissionais no interior do estado. Desse modo, os contextos históricos da época corroboraram para a criação do ensino normal na cidade de Foz do Iguaçu.

Para Lima (2001) a chegada dos colonos oriundos de Santa Catarina e Rio Grande do Sul, em virtude das terras férteis e baratas, e dos grandes colonizadores que se estabeleceram na região deu origem a novas cidades, aumentou a população na região e, consequentemente, a necessidade de mais professores. A primeira Escola Normal Secundária foi a primeira instituição pública do oeste do estado a ofertar o nível escolar secundário, todas essas transformações contribuíram para que a educação no município desse um grande salto e o Grupo Escolar Bartolomeu Mitre, que funcionava na Avenida Jorge Schimmelpfeng, 351, e ofertava o ensino primário no período diurno, implementou o ginásio no ano de 1951 e, no ano seguinte, foi criado o Curso Normal Regional de Foz do Iguaçu, de nível ginasial, e o Ginásio Estadual.

$$
\text { ISSN 2526-2882 }
$$


Souza (2006), argumenta que a denominação "grupo escolar" surge do projeto político republicano de reforma social e difusão da educação popular. O grupo escolar era o espaço que unia as escolas, consagrando, também, o princípio da igualdade da educação entre os sexos. Localizavam-se, geralmente, no centro do núcleo urbano, evidenciando a importância da educação como responsável pelo progresso do país.

Indo além, no ano de 1957, por intermédio do Decreto $\mathrm{n}^{0}$ 10.336, de 28 de maio de 1957, foi criada a Escola Normal Secundária pública do Oeste do Paraná, mas devido à alteração na regulamentação do ensino normal pelo Decreto $n^{0}$ 17.503, de 1958, deveria ser de aplicação à prática de ensino, ginásio ou, também, Escola Normal Regional, dessa forma, recebeu o nome de "Escola Normal Secundária "Iguaçu", a partir do Decreto nº 18.793, de 28 de agosto de 1958. Na época, o governador era Moysés Lupion e o responsável pela Secretaria Estadual de Educação e Cultura era Vidal Vanhoni.

Ao investigar os diferentes aspectos que possibilitaram a criação dos cursos de formação de professores no Oeste do Paraná, a primeira Escola Normal Secundária pública de Foz do Iguaçu, Sbardelotto (2009), conclui que somente foi possível devido ao apoio de pessoas influentes, econômica e politicamente, da cidade, mas isto não impediu as dificuldades na organização do ensino de matemática como evidenciado nas reflexões seguintes.

Portanto, os fatores políticos e econômicos influenciaram a criação da primeira Escola Normal Secundária pública do munícipio de Foz do Iguaçu. Entretanto, como será demonstrada a seguir, a sua implementação, apesar do apoio, foi marcada pelas dificuldades impostas devido à distância do município à capital. Todos esses fatores influenciaram na organização do ensino de matemática, conforme se vê no próximo item.

\section{A organização do ensino de Matemática no ensino normal no período de criação da escola analisada}

A preocupação em relação à organização do ensino da matemática não é algo recente, Miorim(1998) afirma que, no início do século XX, ocorreu um movimento considerado como primeiro Movimento Internacional visando à modernização das escolas de nível médio, reforçando que o objetivo do ensino de matemática era contribuir com o desenvolvimento do raciocínio por meio da lógica dedutiva.

[...] intelectuais, diretamente ligadas à utilidade e aplicações da matemática. [...] Para que esses objetivos pudessem ser alcançados, era necessário que as exigências advindas da nova psicopedagogia, e que estavam na base do Movimento da Escola Nova, fossem observadas: um ensino orientado segundo o grau de desenvolvimento mental, baseado no interesse do aluno, que deveria partir da intuição e apenas aos poucos ir introduzindo o raciocínio lógico, que enfatizasse a descoberta, e não a memorização (MIORIM, 1998, p. 94-95).

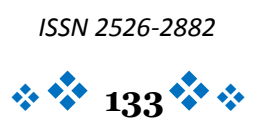


A autora enfatiza que estas ideias aproximaram do Brasil, graças a Euclides Roxo, professor do Colégio D’Pedro II no Rio de Janeiro, que as implementou no referido estabelecimento de ensino, na década de 1920, influenciando as políticas educacionais por meio dos Decretos: no 19890, de 18/04/1931 e n⿳0 21241, de 04/04/1932. Na época, Francisco Campos era o ministro do Ministério da Educação e Saúde Pública, que as implementou, também, nas escolas secundárias brasileiras. Indicava que os professores de matemática precisam preocupar-se com a metodologia de ensino, pois têm a responsabilidade de apresentar os conteúdos favorecendo aos alunos ao envolvimento. As proposições relacionadas ao ensino de matemática de Euclides Roxo influenciaram a reforma do sucessor de Francisco Campos, Gustavo Capanema, assumindo o Ministério da Educação e Saúde Pública em 1934.

Segundo Valente (2004), a reforma de Francisco Campos traçou as diretrizes para a organização do ensino de matemática no que se refere aos conteúdos a serem ensinados, bem como à metodologia, tendo em vista que a nova disciplina intitulada matemática uniu aritmética, álgebra e geometria. Com relação à Reforma de Gustavo Capanema, limitou-se a distribuir os conteúdos de matemática nas diferentes séries do ensino secundário.

No entanto, as diferentes reformas não receberam o apoio de todos os professores, um desses foi Osvaldo Sangiorgi, catedrático de matemática do Instituto Feminino de Educação "Padre Anchieta" de São Paulo e assistente da seção de Matemática da Faculdade de Filosofia, Ciências e Letras da Universidade Mackenzie, que expôs os problemas nos programas vigentes, indicando a necessidade de uma formação matemática diferenciada para os normalistas, desta forma, elaborou um novo Programa para o ensino da matemática no ensino normal que foi oficialmente concretizado no estado de São Paulo como se pode verificar:

[...] a concretização de novos programas para o Ensino Normal de São Paulo, de acordo com a Portaria 49, de 4-12-54, do Diretor Geral do Departamento de Educação, em substituição aos programas de então que se apresentavam completamente superados. Com a adoção do novo programa de Matemática e Estatística (o que vem publicado) vingou o salutar princípio de que as futuras professoras primárias levassem como bagagem fundamental de sua formação profissional, no que respeita a Matemática e Estatística, tão somente a aritmética prática, a geometria prática e noções de Estatística aplicada à Educação, ao invés de se aprofundarem em 'altas matemáticas' 35 como objetivavam os antigos programas que sem desmerecê-los, atendiam razões pertinentes a sua época.[...] Teriam agora, em três anos de curso Normal, o sabor de conhecerem, dentro da aritmética e geometria, a razão dos "porquês" tão comuns nas perguntas de seus futuros alunos (SANGIORGI, 1957, p. 20-21) [Grifo nosso].

Pelo exposto, novos encaminhamentos pautaram a formação matemática dos futuros professores primários oportunizando, conforme afirma Sangiorgi (1957), o "saber o que

35 Sangiorgi (1954, p. 12) exemplifica as altas matemática como “cálculo de pi, equações irracionais, entre outros”. ISSN 2526-2882 
ensinar" e "como ensinar" e, ainda, contando com a colaboração dos professores que foram ouvidos para, assim, se sentirem confiantes na implementação da mudança na organização do ensino de matemática. O referido "Programa Matemática e Estatística” criado pelo autor e publicado na Revista intitulada “Atualidades Pedagógicas”, em 1957.

Analisando o "Programa Matemática e Estatística" sublinha que houve a implementação do referido programa no estado do Paraná, mas com diferencial do estado de São Paulo, onde as disciplinas matemática e estatística foram separadas, porém, com o mesmo objetivo de proporcionar a formação matemática aos futuros professores primários, pautados, a partir, da prática da aritmética e da geometria, também, das ideias fundamentais da estatística.

Desse modo, constata-se que a primeira turma da Escola Normal Secundária Pública de Foz do Iguaçu iniciou em 1957, tinha um alinhamento na organização do ensino de matemática pautado em Osvaldo Sangiorgi. Assim, dando continuidade à pesquisa, foram analisados os documentos inativos da referida instituição de ensino e, a seguir, serão apresentadas as reflexões.

\section{Analisando e discutindo os documentos inativos da escola investigada acerca da organização do ensino de matemática}

A presente pesquisa, de caráter bibliográfico e documental, realizada no ano de 2017, pelo grupo de pesquisa Formação e Educação Matemática (Formem), que corrobora com Gil (2010) quando afirma que o pesquisador deve ser cauteloso em sua realização, analisando possíveis equívocos e utilizando fontes diversas que contribuam para detectar incoerências ou contradições.

Neste sentido, primeiramente, analisa-se como pesquisa bibliográfica para compreender a trajetória histórica do ensino normal na região do oeste do Paraná. Por conseguinte, foram analisadas as leis Paraná (1955, 1958); Brasil (1946) e, também, os documentos inativos da primeira escola normal secundária de Foz do Iguaçu, pois

As leis, relatórios e demais documentos aqui considerados representam "vestígios" que possibilitam perceber as concepções sobre a educação e o modo como deveriam ser preparados os professores, bem como a função que lhes era atribuída pelo Estado. Constituem-se ainda em um conjunto de ideias e ações determinadas e aceitas oficialmente como passíveis de aplicação em determinado momento e em determinada realidade (MIGUEL, 2008, p. 02).

Saviani (2004) salienta:

As fontes estão na origem, constituem o ponto de partida, a base, o ponto de apoio da construção historiográfica que é a reconstrução, no plano do

ISSN 2526-2882 
conhecimento, do objeto histórico estudado. Assim as fontes históricas não são a fonte da história, ou seja, não é delas que brota e flui a história. Elas, enquanto registros, enquanto testemunho dos atos históricos, são a fonte do nosso conhecimento histórico, isto é, é delas que brota, é nelas que se apoia o conhecimento que produzimos a respeito da história (SAVIANI, 2004, p. 5-6).

Partindo disso, o quadro 1 a seguir indica os arquivos inativos da primeira Escola Secundária pública de Foz do Iguaçu.

\section{Quadro 1: Guia de documentos da Escola Normal}

\begin{tabular}{|l|c|l|}
\hline \multicolumn{1}{|c|}{ Documentos } & Ano/ Período & \multicolumn{1}{c|}{ Localização } \\
\hline $\begin{array}{l}\text { Ata de provas parciais, orais, } \\
\text { exames de segunda época e curso } \\
\text { de admissão da Escola Normal } \\
\text { Secundária de Foz do Iguaçu. }\end{array}$ & $1957-1969$ & $\begin{array}{l}\text { Colégio Agrícola Estadual Manoel } \\
\text { Moreira Pena }\end{array}$ \\
\hline Registros de Licença & $1939-1951$ & Colégio Estadual Bartolomeu Mitre \\
\hline Termo de posse & $1952-1972$ & Colégio Estadual Bartolomeu Mitre \\
\hline Termo de exercício & $1957-1968$ & Colégio Estadual Bartolomeu Mitre \\
\hline Atas de encerramento de aulas & $1956-1980$ & Colégio Estadual Bartolomeu Mitre \\
\hline
\end{tabular}

Fonte: Documentos Inativos da primeira Escola Normal Secundária pública de Foz do Iguaçu, que se encontram no Colégio Agrícola Estadual Manoel Moreira Pena e Colégio Estadual Bartolomeu Mitre e organizados pelas pesquisadoras.

No período da criação das escolas analisadas, os professores no estado do Paraná eram contratados conforme previsão no Decreto de 1955 e, segundo a mensagem do governador da época, indicava a falta de professores. Dessa forma, a escola analisada acabou tendo o quadro docente com formação mínima exigida pelas regulamentações, de acordo com Sbardelotto:

Muitas das disciplinas desta Escola, ministradas por médicos, advogados, militares, esposas de militares, tinham um caráter geral em função da formação desses professores, contrariando a orientação nacional e estadual para esse curso secundário. Devido ao perfil do corpo docente, o ensino na Escola Normal Secundária "Iguaçu" acabou mesclando uma formação técnica e uma formação geral, enquanto as disciplinas práticas estavam mais voltadas para o trabalho nas escolas seriadas do que nas escolas isoladas multisseriadas, embora essas últimas estivessem mais necessitadas de professores habilitados (SBARDELOTTO, 2009, p. 182).

Analisando os registros de licença, posse e exercício levantou-se a falta de professores que era evidenciada pelos idealizadores da referida escola bem como pelo próprio governo do estado do Paraná da época que considerava a ampliação destas escolas como peça fundamental para a mudança desse quadro. 
Com relação ao exame de admissão da primeira turma, constatou-se um alinhamento com o proposto pelo estado de São Paulo que, segundo Valente (2011), é marcado pelos inúmeros exames de admissão nos diferentes níveis de ensino e, os alunos oriundos de famílias que tinham condições financeiras de contratar um professor particular, visando ao preparo para os exames de admissão, acabavam tendo mais oportunidades, e no estado de São Paulo também foi instituído, em 1957 ,o vestibular como critério de seleção para o ensino normal devido ao aumento expressivo de interessados.

Cumpre lembrar que, segundo Oliveira (2001), as propostas de organização de ensino do estado de São Paulo influenciavam o estado do Paraná desde a instauração da Primeira República, o que acabava desconsiderando a realidade social do estado.

Para Oliveira (2001, p. 143) o estado do Paraná, por meio de seus regulamentos vislumbravam corroborar "na organização escolar para compatibilizar uma sistemática de ensino moderna e eficiente". Desse modo, "as inovações na educação provenientes da Europa e dos Estados Unidos foram colocadas em prática nos estados economicamente mais prósperos, como São Paulo, servindo de referência e modelo para a sua implantação no Paraná”.

Nas Atas de provas parciais, orais, exames de segunda época e curso de admissão da Escola Normal Secundária de Foz do Iguaçu, de fevereiro de mil novecentos e sessenta, o alinhamento das regulamentações do estado do Paraná para o ensino normal, vai ao encontro do critério de seleção proposto pelo estado de São Paulo, pois apesar de não terem o número mínimo de alunos exigidos, utilizaram o vestibular como critério de seleção e na imagem 1, têm-se a foto da primeira turma.

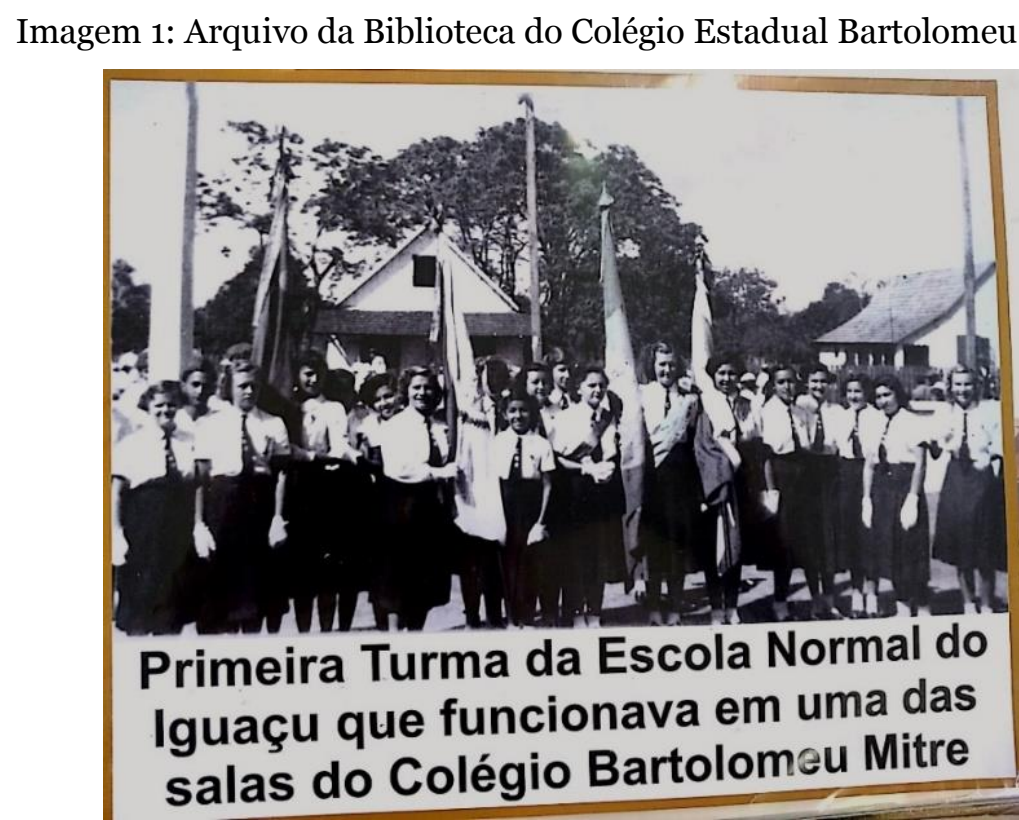

Fonte: Arquivo digital das pesquisadoras.

$$
\text { ISSN 2526-2882 }
$$


Pode-se observar na imagem 1 a primeira turma foi composta predominante de mulheres. Ademais, o exame de admissão da primeira turma constatou-se pela Ata de provas parciais, orais, exames de segunda época e curso de admissão da Escola Normal Secundária de Foz do Iguaçu, que a prova escrita de aritmética corroborou para o alto índice de reprovação, pois dos vinte e nove inscritos, dezenove foram aprovados, sendo dezesseis mulheres e três homens.

Vale ressaltar que a primeira turma era oriunda das famílias que representavam a elite da época, contradizendo a luta para criação da escola indicar objetivos para a profissionalização dos professores dos cursos normais regionais, isto não aconteceu, pois, os alunos, em sua maioria, vinham do ginásio.

A análise dos documentos e a revisão bibliográfica vai ao encontro de Romanelli (1986) o qual afirma que os alunos matriculados nas escolas normais, nos diferentes estabelecimentos de ensino na época, eram, na maioria, a população feminina, pois os familiares tinham condições financeiras. De fato, ao analisar os documentos dos alunos da primeira turma, há indícios que se formaram predominantemente de filhos das pessoas influentes da época e, apesar do ensino normal vislumbrar atender os professores que atuavam, o que ocorreu foi atender os alunos que cursavam o ginásio.

Considera-se importante apresentar o quadro 2, no qual constam as disciplinas que foram ministradas na primeira turma, onde não há registros de implementação da organização do ensino de matemática proposto por Osvaldo Sangiorgi.

Quadro 2: Disciplinas por séries da primeira turma da Escola Normal Secundária de Foz do Iguaçu1958 a 1960

\begin{tabular}{|l|l|l|}
\hline \multicolumn{1}{|c|}{$\mathbf{1}^{\mathbf{a}}$ série (1958) } & \multicolumn{1}{|c|}{$\mathbf{2}^{\mathbf{a}}$ série (1959) } & \multicolumn{1}{c|}{$\mathbf{3}^{\mathbf{a}}$ série (1960) } \\
\hline Português & Português & $\begin{array}{l}\text { Didática da Educação } \\
\text { Primária }\end{array}$ \\
\hline Matemática & Matemática & Psicologia educacional \\
\hline Física e Química & $\begin{array}{l}\text { Didática da Educação } \\
\text { Primária }\end{array}$ & Sociologia educacional \\
\hline $\begin{array}{l}\text { Anatomia e fisiologia } \\
\text { humanas }\end{array}$ & Biologia educacional & Filosofia da Educação \\
\hline $\begin{array}{l}\text { Didática da Educação } \\
\text { Primária }\end{array}$ & Psicologia educacional & Higiene e educação sanitária \\
\hline Estudos paranaenses & Higiene e educação sanitária & Música e Canto \\
\hline Desenho e artes aplicadas & Música e Canto & $\begin{array}{l}\text { Educação Física, recreação e } \\
\text { jogos }\end{array}$ \\
\hline Música e Canto & $\begin{array}{l}\text { Educação Física, recreação e } \\
\text { jogos }\end{array}$ & Desenho \\
\hline $\begin{array}{l}\text { Educação Física, recreação e } \\
\text { jogos }\end{array}$ & Desenho & \\
\hline
\end{tabular}

Fonte: Organizado pelas autoras a partir dos documentos inativos da Escola Normal Secundária de Foz do Iguaçu. 
Em síntese, ao comparar o quadro 2 que determina as disciplinas ministradas na escola analisada com as determinações de Brasil (1946), as quais indicavam as disciplinas mínimas, tendo os estados autonomia de complementá-las, no caso do estado do Paraná estas foram efetivadas por meio de Paraná $(1955,1958)$, que regulamentava o ensino normal, e indicava o alinhamento com a proposta idealizada por Osvaldo Sangiorgi, pois aparece a disciplina de estatística.

Conforme Sangiorgi (1957), o idealizador das mudanças no "Programa Matemática e Estatística”, implementado no estado de São Paulo, vigorava também no Paraná, mas como um diferencial, pois, a Estatística era concebida como uma disciplina independente. Com relação ao tempo de execução, estava sendo discutido desta forma: poderia ser organizado em dois anos letivos com três aulas semanais, ou três anos letivos com duas aulas semanais.

No entanto, analisando os documentos inativos da primeira Escola Normal secundária pública de Foz do Iguaçu, não há registros da disciplina de estatística na primeira série, em 1958. Na imagem 2 e 3 há indícios da implementação desta mudança no ano de 1960, quando a segunda turma do ensino normal secundário acabou sendo contemplada.

Imagem 2: Ata de provas parciais, orais, exames de segunda época e curso de admissão da Escola Normal Secundária de Foz do Iguaçu

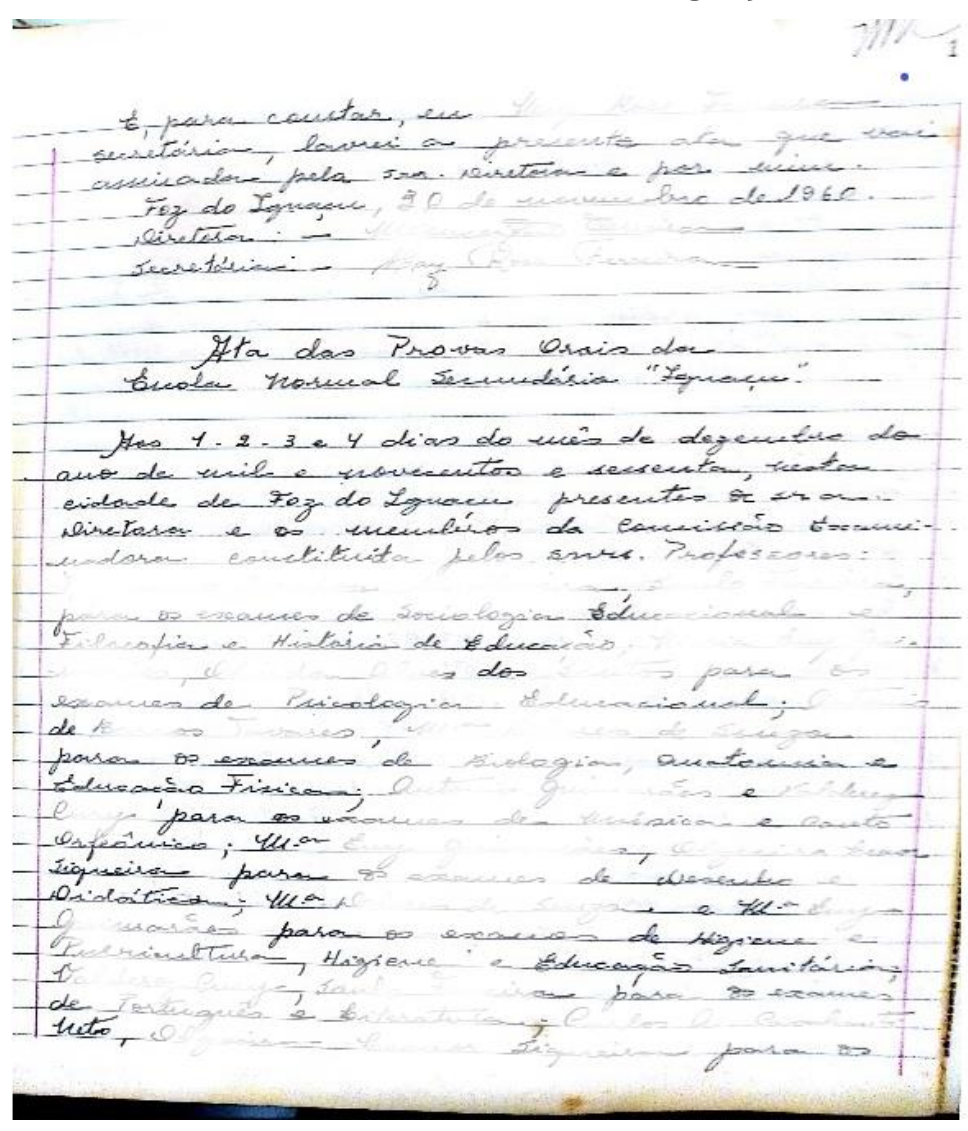

Fonte: Arquivo digital das pesquisadoras.

ISSN 2526-2882 
Imagem 3: Ata de provas parciais, orais, exames de segunda época e curso de admissão da Escola Normal Secundária de Foz do Iguaçu

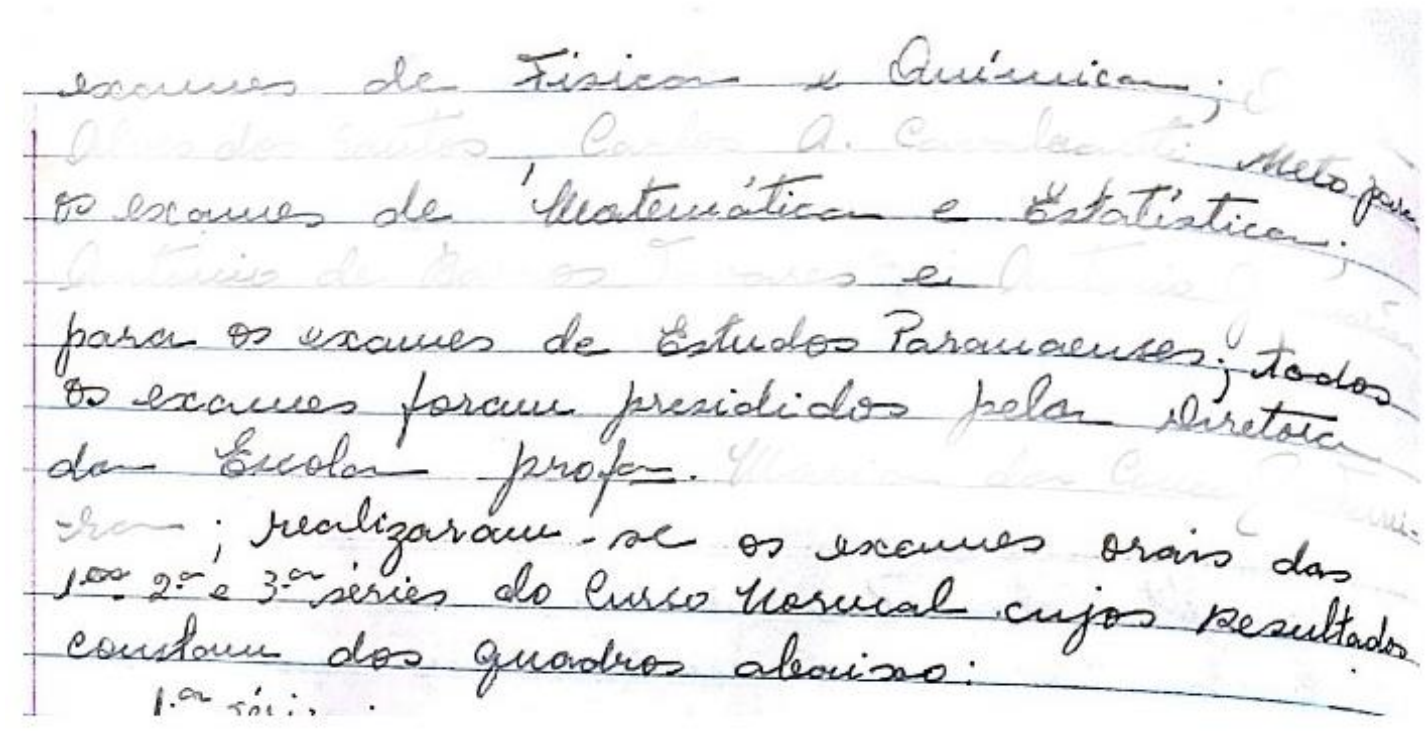

Fonte: Arquivo digital das pesquisadoras.

Assim, nos documentos inativos da primeira Escola Normal secundária pública de Foz do Iguaçu, não há registros da disciplina de estatística na primeira série, em 1958, e somente há indícios da implementação desta mudança no ano de 1960. Como consta na Ata de provas parciais, orais, exames de segunda época e curso de admissão da Escola Normal Secundária de Foz do Iguaçu que as propostas idealizadas por Osvaldo Sangiorgi foram implementadas segundos os documentos na segunda turma do ensino normal secundário.

Desse modo, para Oliveira (2001), mesmo que as propostas de organização de ensino do estado de São Paulo influenciavam o estado do Paraná desde a instauração da Primeira República, o que acabava desconsiderando a realidade social do estado.

[...] No Paraná, diversos foram os Regulamentos tentando alterações na organização escolar para compatibilizar uma sistemática de ensino moderna e eficiente. As inovações na educação provenientes da Europa e dos Estados Unidos foram colocadas em prática nos estados economicamente mais prósperos, como São Paulo, servindo de referência e modelo para a sua implantação no Paraná (Oliveira, 2001, p. 143).

Neste sentido, apesar da regulamentação do ensino normal Paraná indicar mudança na formação matemática no ensino normal idealizadas por Osvaldo Sangiorgi, na prática estas não foram implementadas conforme indicado pelos documentos e a primeira turma da escola analisada manteve a formação matemática seguindo as regulamentações anteriores que era 
criticada como inadequada. De acordo com Oliveira (2001, p. 145), no estado do Paraná, mesmo que houvesse imposições, via legislação, para mudança no ensino visando a inovação "à realidade socioeconômica, evidenciaram o grau de distanciamento entre o que se pretendia fazer e o que se podia fazer".

Desse modo, as inovações na organização do ensino de matemática ficaram distantes da primeira turma da Escola Normal Secundária pública de Foz do Iguaçu, não há registros documentais e as condições estruturais inviabilizaram tais acontecimentos. De fato, o ensino normal tornou-se acessível no interior do Estado, mas não com as condições adequadas para a formação dos futuros professores primários.

\section{Considerações finais}

Neste artigo discutiu-se a organização do ensino da matemática na primeira turma da Escola Normal Secundária pública do município de Foz do Iguaçu. Análise relevante para uma reflexão mais atenta de como fatores econômicos, políticos e sociais são determinantes para a implementação de possíveis mudanças determinadas pelas regulamentações legais. Como ocorrido com a criação da primeira Escola Normal Secundária pública de Foz do Iguaçu que somente foi possível porque, na época, havia vários interesses políticos, inclusive, imposições de organismos internacionais.

O estado do Paraná acabou organizando seu ensino seguindo a proposta do estado de São Paulo, ignorando suas próprias demandas e especificidades. Partindo de uma pesquisa bibliográfica e documental, verificou-se que, apesar da indicação de mudança na organização do ensino da matemática no ensino normal, idealizada por Osvaldo Sangiorgi, sua implementação ocorreu, primeiramente, no estado de São Paulo, depois foi disseminada para vários estados, incluindo o Paraná.

De fato, a regulamentação do ensino normal proposto por Paraná (1955-1958) indica terem sidos colocadas em prática. No entanto, apesar da escola analisada iniciar suas atividades no ano de 1958, não há vestígios que a turma analisada tenha sido contemplada com a referida formação matemática que só ocorreu a partir do ano de 1960, quando a primeira turma estava na terceira série e não havia a disciplina de estatística.

Constatou-se, também, que o quadro docente era deficitário, corroborando para que professores sem a formação adequada atuassem no ensino normal o que, consequentemente, dificultava a articulação das disciplinas com o ensino primário, como ressaltado por Osvaldo Sangiorgi que indicava que a formação matemática no ensino normal deveria organizar-se partindo da prática da aritmética e ensino de estatística, possibilitando saber "o que" e "como" ensinar para seus futuros alunos. 
Outro ponto negativo para organização do ensino de matemática era a estrutura da instituição de ensino, que não tinha biblioteca adequada, tampouco materiais pedagógicos. Concluiu-se, dessa forma, que as mudanças na organização do ensino da matemática não se efetivaram na escola analisada por meio da análise dos documentos existentes, pois as condições materiais indicaram limitação para que pudessem, de fato, ocorrer.

\section{Referências}

ALMEIDA, J. S. Vestígios para uma reinterpretação do magistério feminino em Portugal e no Brasil a partir do século XIX. In: SAVIANI, D. et al. O legado educacional do século XIX. 2. ed. Campinas, SP: Autores Associados, 2006.

GIL, A. C. Métodos e técnicas de pesquisa social. 6. ed. São Paulo: Atlas, 2010.

LIMA, P. Foz do Iguaçu e sua história. Foz do Iguaçu: Copyright, 2001.

MIORIM, M. A. Introdução à História da Educação Matemática. São Paulo: Ed. Atual, 1998.

MIGUEL, M. E. B.; ALBONI, M. D. O. V. A Escola Nova no Paraná: avanços e contradições. Revista Diálogo Educacional, Curitiba, v. 5, n.14, p. 93-100, jan./abr. 2005. Disponível $\quad$ em: $\quad<$ file://C:/Users/susimeire/Downloads/7355-11984-1SM\%20(1).pdf>. Acesso em: 06 de nov. de 2016.

MIGUEL, M. E. B. A escola normal no paraná: instituição formadora de professores e educadora do povo. 2008 Disponível em: < http://sbhe.org.br/novo/congressos/cbhe5/pdf/9.pdf > Acesso em: o6 de jun. de 2016.

ROMANELLI, O. O. História da Educação no Brasil (1930/1973), $8^{a}$ ed., Petrópolis: Vozes, 1986.

OLIVEIRA, M.C. M. Organização Escolar no início do século XX: o caso do Paraná. Educar, Curitiba, n. I 8, p. 143-155. 2001. Editora da UFPR. Disponível em: <http://www.scielo.br/pdf/er/n18/n18ao9.pdf>. Acesso em: 10 de ago. de 2016.

SANGIORgI, O. Objetivos do Ensino de Matemática. Atualidades Pedagógicas. Ano V, n. 28, jul./ago., p.9 - 12, 40, 1954. Disponível em: <file://C:/Users/susiv/Downloads/Atualidades\%2opedag\%C3\%B3gicas\%2O\%201954\%20-\%20n.\%2028.PDF>. Acesso em: o3 de nov. de 2016.

. Programas de Matemática e Estatística para os Cursos Normais. Atualidades Pedagógicas. Ano VIII, n. 41, mai./ago., p.20 - 26, 1957. Disponível em: <file://C:/Users/susiv/Downloads/Atualidades\%2opedag\%C3\%B3gicas\%20\%2019 57\%20-\%20n.\%2041.PDF>. Acesso em: o7 de ago. de 2016. 
SAVIANI, D. Educação brasileira: estrutura e sistema. 11. ed. São Paulo: Cortez Autores Associados, 2012.

Formação de professores: aspectos históricos e teóricos do problema no contexto brasileiro. Revista Brasileira de Educação v. 14 n. 40 jan./abr. 2009. Disponível

em:<http://poseducacaoifbaiano.com.br/wpcontent/uploads/2014/11/Forma\%C3\% A7\%C3\%A3o-de-professores-aspectos-hist\%C3\%B3ricos-e-te\%C3\%B3ricos-doproblema-no-contexto-brasileiro.pdf > . Acesso em: 04 de jan. de 2017.

. História da formação docente no Brasil: três momentos decisivos. Revista Educação, Santa Maria, v. 30, n. 2, p.11-26, 2005. Disponível em: <https://periodicos.ufsm.br/reveducacao/article/view/3735/2139>. Acesso em: 14 de fev. de 2017.

Breves considerações sobre fontes para a história da educação. In: LOMBARDI, J. C. E NASCIMENTO, M. I. M. (Org). Fontes, História e Historiografia da Educação. Campinas: Autores Associados, 2004.

SBARDElotTO, D. K. O Desenvolvimento dos Cursos de Formação de Professores Primários na Fronteira Oeste Paranaense: a criação da primeira Escola Normal Secundária pública de Foz do Iguaçu e do Oeste do Paraná, 2009, 214 f.

SOUZA, Rosa F. de. Espaço e da civilização: origens dos grupos escolares no Brasil. In: SAVIANI, D. et al. O legado educacional do século XX no Brasil. 2. Ed. Campinas: Autores Associados, 2006.

VAlENTE, W. R. (Org.). Euclides Roxo e a modernização do ensino de matemática no Brasil. Brasília: Editora da UnB, 2004.

. A matemática na formação do professor do ensino primário: São Paulo, 1875-1930. São Paulo: Annablume, 2011.

O Lugar da Matemática Escolar na Licenciatura em Matemática. 2013. Disponível em : < http://www.redalyc.org/pdf/2912/291229747012.pdf > Acessado em: 10 de fev. 2017.

\section{Fontes documentais}

BRASIL. Lei Orgânica do Ensino Normal. Decreto-lei n. 8.53o, de 2 de janeiro de 1946. Disponível em: <http://www2.camara.leg.br/legin/fed/declei/19401949/decreto-lei-8530-2-janeiro-1946-458443-publicacaooriginal-1-pe.html>. Acesso em: 01 de maio. de 2016.

BRASIL Lei no 9.394, de 20 de dezembro de 1996. Estabelece as diretrizes e Bases da educação Nacional. Ministério da Educação, 1996. Disponível em: < ISSN 2526-2882 
http://www.planalto.gov.br/ccivil_03/leis/L9394.htm > Acesso em: 01 de fev. de 2017.

ESCOLA NORMAL SECUNDÁRIA IGUAÇU. Ata de provas parciais, orais, exames de segunda época e curso de admissão da Escola Normal Secundária de Foz do Iguaçu. Foz do Iguaçu, Paraná.

ESCOLA NORMAL SECUNDÁRIA IGUAÇU. Ata de provas parciais, orais, exames de segunda época e curso de admissão da Escola Normal Secundária de Foz do Iguaçu. Foz do Iguaçu, Paraná.

ESCOLA NORMAL SECUNDÁRIA IGUAÇU. Registros de Licença. Foz do Iguaçu, Paraná.

ESCOLA NORMAL SECUNDÁRIA IGUAÇU Termo de posse. Foz do Iguaçu, Paraná. ESCOLA NORMAL SECUNDÁRIA IGUAÇU Termo de exercício. Foz do Iguaçu, Paraná. ESCOLA NORMAL SECUNDÁRIA IGUAÇU Atas de encerramento de aulas. Foz do Iguaçu, Paraná.

\section{Biografia Resumida}

Patrícia Sandalo Pereira. Professora da Universidade Federal de Mato Grosso do Sul (UFMS). Doutora em Educação Matemática pela Universidade Estadual Paulista Júlio de Mesquita Filho (UNESP/Rio Claro - SP). Atua no curso de Licenciatura em Matemática e nos programas de pós-graduação em Educação Matemática e em Ensino de Ciências, ambos da UFMS.

Link Lattes: http://Link Lattes.cnpq.br/9126213537245312

e-mail: patricia.pereira@ufms.br

Susimeire Vivien Rosotti de Andrade. Professora da Universidade Estadual do Oeste do Paraná (UNIOESTE/Foz do Iguaçu - PR). Doutoranda em Educação Matemática pela Universidade Federal de Mato Grosso do Sul (UFMS). Mestre em Educação para a Ciência e a Matemática pela Universidade Estadual de Maringá (UEM). Atua no curso de Licenciatura em Matemática da UNIOESTE.

Link Lattes: http://Link Lattes.cnpq.br/7645006700133174 e-mail: susirosotti@gmail.com 